\title{
Study of Carcinoma Breast in Women under 40 Year of age at A Tertiary Care Hospital in Central India
}

\author{
Sanjay D. Dakhore ${ }^{1}$, Nilesh P. Mangam², Shilpa Namdev Pande ${ }^{3}$, Ritesh M. Bodade ${ }^{4}$, Asmita dhurve $^{5}$, Gaurav G $^{2}$ \\ Jannawar 6
}

${ }^{1}$ Assistant Professor, Department of surgery Government medical college and hospital Nagpur, ${ }^{2}$ Assistant Professor, Department of surgery Government medical college and hospital, Nagpur, ${ }^{3}$ Senior resident, Department of radiodiagnosis, Tata Memorial Hospital, mumbai, ${ }^{4}$ Assistant Professor, Department of surgery Government medical college and hospital, Nagpur, ${ }^{5}$ Assistant Professor, Department of surgery Government medical college and hospital, Nagpur, ${ }^{6}$ Consultant Plastic Surgeon, Nagpur, Maharashtra, India

Corresponding author: Nilesh P Mangam, Assistant Professor, Department of Surgery, Government Medical College and Hospital Nagpur, Maharashtra, India

DOI: 10.21276/ijcmsr.2018.3.3.12

How to cite this article: Sanjay D. Dakhore, Nilesh P. Mangam, Shilpa Namdev Pande, Ritesh M. Bodade, Asmita dhurve, Gaurav G Jannawar. Study of carcinoma breast in women under 40 year of age at a tertiary care hospital in central India. International Journal of Contemporary Medicine Surgery and Radiology. 2018;3(3):C53-C58.

\section{A B S T R A C T}

Introduction: Breast cancer among young women is a relatively uncommon. Many of the times the diagnosis is delayed in these patients owing to the reluctance of surgeons to subject young females to mammography because of the involved radiation. Current study was conducted to study various aspects of carcinoma breast occurring in patients younger than 40 years of age.

Material and Methods: This was a prospective study conducted in the surgery department in which 57 patients less than 40 years of age and diagnosed to be having carcinoma breast were included on the basis of a predefined inclusion and exclusion criteria. The risk factors, clinical presentation, staging and outcome were studied in these cases. Statistical analysis was done using SPSS16.0 version software. P-value less than 0.05 was taken as statistically significant.

Results: The most common affected age group was found to be between $35-40$ years (56.14\%). Common symptoms included lump in breast (100\%), pain (19.29\%) and discharge (17.54\%). Majority of the patients had their first child birth at age less than 20 years. Upper outer quadrant was the most commonly affected site (56.14\%) and nipple retraction (19.29\%) was the most common sign in the studied cases. Most common tumor and clinical staging were found to be T3 (33.33\%) and T III B $(28.07 \%)$ respectively. Surgery and hormonal therapy were the most common treatment modalities given to these patients (85\%). Most common histopathological type was found to be infiltrating ductal carcinoma.

Conclusion: Our study concludes that age less than $40 \mathrm{yrs}$ is associated with diagnosis of breast cancer at an advanced stage and young patients presenting with breast lumps should not in any way be considered different from relatively older patients and all standard screening and diagnostic investigations must be carried out for early diagnosis and proper interventions.

Key words: Carcinoma Breast, Young Females, Histopathology, Staging

\section{INTRODUCTION}

Carcinoma breast is one of the most common cancer related morbidity and mortality seen in postmenopausal women. Over the past several decades there has been a steady and large increase in the incidence of the disease ${ }^{1} .1$ in 8 women has a lifetime risk of developing breast cancer. Changes in dietary patterns, increased prevalence of obesity, use of contraceptive hormones and hormone replacement therapy in perimenopausal women are the important factors responsible for increased incidence of breast carcinoma throughout the world ${ }^{2}$. One of the other important cause is increase utilization of screening mammography which may be responsible for detection of asymptomatic patients having carcinoma breast. In India breast cancer is the second most common cause cancer related deaths. The natural history of breast cancer is characterized by heterogenicity amongst patients and long duration of disease ${ }^{3}$.

Breast carcinoma in young women (before the age of 40 years) is reported to be uncommon comprising only of 5-7\% of all the cases diagnosed with carcinoma breast. Certain regions and ethnicities are found to have increased risk of developing carcinoma beast at a relatively younger age $\mathrm{e}^{4}$. A relatively higher proportion of the population in middle east and Africa are found to be having breast carcinoma below the age of 40 years, reaching as high as up to $20 \%$. The exact cause of such a propensity in certain regions and ethnicities are not known but underlying genetic differences and environmental factors are thought to be the important contributing factors ${ }^{5}$.

Age alone has been shown to be an independent risk factor 
for breast cancer. Breast cancer in young females is unique in the sense that breast cancer in young females is itself a poor prognosis factor because of greater incidence of advanced stage of disease at presentation with high risk of recurrence ${ }^{6}$. The diagnosis in young females is usually delayed because of low index of, firm breasts hindering clinical and radiological interpretation also causing missing of small breast lumps. Additionally, primary care gynecologists or surgeons may also be reluctant to advice mammography in young patients because of the involved radiation. Breast carcinoma in young patients are characterized by decreased hormone sensitivity, higher levels of human epidermal growth factor receptor 2 expressions, aggressive growth patterns and poor outcomes as compared to the carcinomas encountered in patients with relatively elderly age group. Relatively late detection and more aggressive nature of breast carcinoma is responsible for poor outcomes in these patients. Early onset breast cancer not only has different molecular or etiological basis but also has psychological aspect too, as patient loses breast in sexually active phase of life when it is most desirous to have one ${ }^{7}$.

Management of the breast cancer requires multidisciplinary approach comprising of surgeons, radiotherapists, medical oncologists, pathologists and other professionals such as counselors. Surgery with adjuvant radiotherapy has now become a standard procedure for patients with breast cancer ${ }^{8}$. This was a hospital based observational study conducted to study various aspects of carcinoma breast occurring in patients younger than 40 years of age. Our emphasis was in comparing tumor characteristics between very young ( $\leq$ 30 years) and young (30- 40 years) patients and to compare tumor characteristics between operable and advanced stage cancers.

\section{MATERIAL AND METHODS}

This was a hospital based observational study conducted at department of surgery. Total 57 patients who fulfilled predefined inclusion criteria and were below 40 years of age were included in study. Any patient having any of the exclusion criteria was excluded from the study. The duration of the study was 2 years.

A detailed history including history of carcinoma breast in any of the family members was noted. Demographic details of all the patients were noted. A thorough clinical examination was done in all the cases. Routine investigations such as complete blood count, Bleeding and Clotting Time, routine urine examination, Renal and hepatic function tests, random blood sugar, ECG, chest X-Ray was done in all the cases. All patients included in this study had undergone mammography, sonomammography and FNAC to know histopathology study of specimen.

The patients were treated by various types of mastectomies (simple mastectomy, simple mastectomy with axillary clearance, modified radical mastectomy) and by chemotherapy, radiotherapy and hormonal therapy as indicated.

Cases were followed up till the end of study, the follow up included clinical examination for recurrence of the tumor at the operated site, recurrence in axilla and postoperative complications like lymphedema. Patients who complained of symptoms of metastasis were investigated to find the metastasis.

\section{Inclusion Criteria}

1. All cytologically or histologically proven cases of carcinoma breast.

2. Age of the patients $\leq 40$ years.

3. Patients giving informed consent to be the part of study.

\section{Exclusion criterion}

1. Patients not giving consent.

2. Patients refusing treatment.

3. Women with pre-existing breast cancer and those who have received any kind of chemo or radiotherapy in the past.

\section{STATISTICAL ANALYSIS}

Data was collected and tabulated into a master sheet and statistical tests were applied to test the significance of association. The results were studied using appropriate statistical methods. All the patients were followed up for a period of two months from starting of treatment. The results were studied using appropriate statistical methods. $\mathrm{P}$ less than equal to 0.05 was taken as statistically significant. Microsoft word and excel were used for generating charts and graphs

\section{RESULTS}

This was a prospective study of carcinoma breast in patients below 40 years of age in which 57 patients were included. The most common affected age group was found to be between

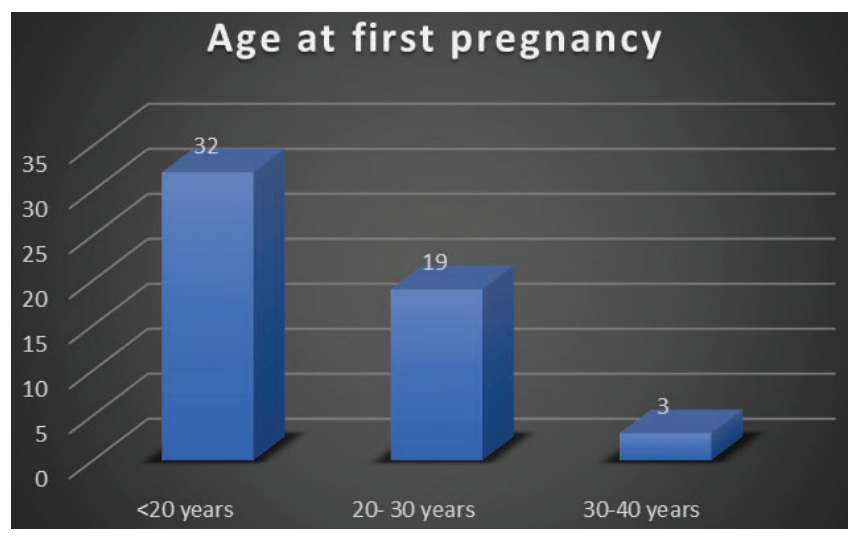

Figure-1: Age at first pregnancy in the studied cases.

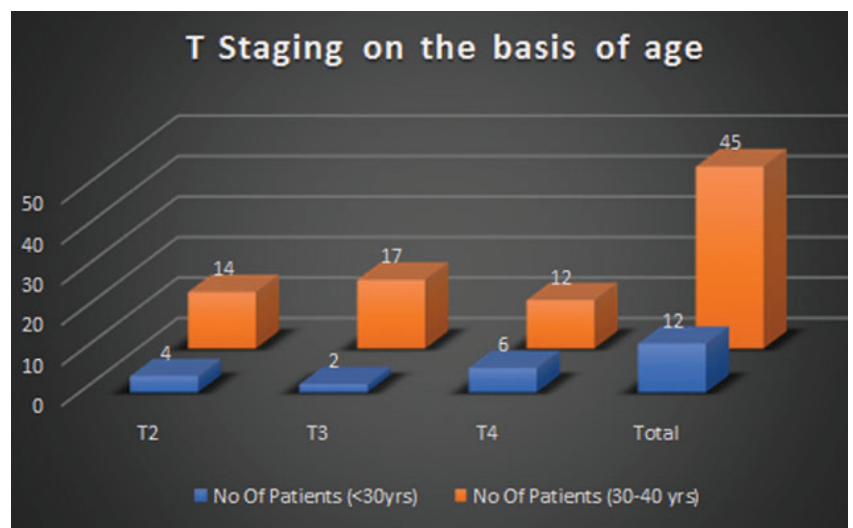

Figure-2: $\mathrm{T}$ Stage wise distribution in young and very young:. 
35-40 years (56.14\%) followed by $30-35$ years $(24.56 \%)$ and 25-30 years (15.78\%). Youngest patient was 19 yrs old girl and oldest of patient was a $40 \mathrm{yrs}$ old lady. The mean age of the studied cases was found to be 35.24 yrs. Family history was positive only in 2 cases (table-1).

Lump in breast was the most common symptom which brought patient to consultation and was present in all the cases $(100 \%)$. The other common symptoms included pain (19.29\%), nipple discharge (17.54\%) and axillary mass (12.28\%). Right sided lumps were more common than left sided ones, with 35 (61.40\%) patients presenting with Right

\begin{tabular}{|l|c|c|}
\hline Age group & $\begin{array}{c}\text { Number of } \\
\text { patients }\end{array}$ & Percentage \\
\hline $15-20$ yrs & 1 & $1.75 \%$ \\
\hline $20-25$ yrs & 2 & $3.50 \%$ \\
\hline $25-30$ yrs & 9 & $15.78 \%$ \\
\hline $30-35$ yrs & 14 & $24.56 \%$ \\
\hline $35-40$ yrs & 32 & $56.14 \%$ \\
\hline Total & 57 & $100 \%$ \\
\hline \multicolumn{3}{|c|}{ Table-1: Age wise distribution of the patients } \\
\hline
\end{tabular}

\begin{tabular}{|l|c|c|}
\hline Symptoms & Number & Percentage \\
\hline Lump & 57 & $100 \%$ \\
\hline Pain & 11 & $19.29 \%$ \\
\hline Discharge & 10 & $17.54 \%$ \\
\hline Axillary mass & 7 & $12.28 \%$ \\
\hline Menstrual irregularity & 4 & $7.01 \%$ \\
\hline Metastatic symptoms & 4 & $7.01 \%$ \\
\hline \multicolumn{2}{|c|}{ Table-2: Symptoms in the studied cases. } \\
\hline
\end{tabular}

\begin{tabular}{|l|c|c|}
\hline Clinical stage & $\begin{array}{c}\text { Number of } \\
\text { patients }\end{array}$ & Percentage \\
\hline II A & 14 & $24.56 \%$ \\
\hline II B & 12 & $21.05 \%$ \\
\hline III A & 10 & $17.54 \%$ \\
\hline III B & 16 & $28.07 \%$ \\
\hline IV & 3 & $5.26 \%$ \\
\hline undetermined & 2 & $3.51 \%$ \\
\hline Total & 57 & $24.56 \%$ \\
\hline \multicolumn{2}{|c|}{ Table-3: TNM staging of the disease. } \\
\hline
\end{tabular}

breast lumps. Nipple discharge was reported to be blood stained in 2 patients (table-2).

Patients' obstetric history was noted and patients were classified according to parity.Majority of the patients (61.40\%) were para 2 or para 1 (19.29\%) (figure-1). Nulliparous women made the smallest group of patients (5.26\%). Majority of the patients had their first child birth at age less than 20 years. 16

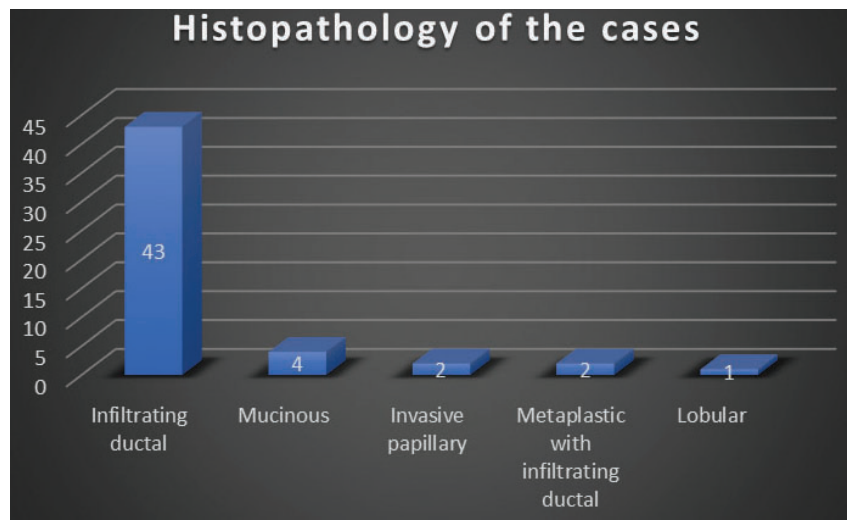

Figure-3: Histopathological subtypes of carcinoma.

\begin{tabular}{|l|c|c|}
\hline Treatment option & $\begin{array}{c}\text { Number of } \\
\text { patients }\end{array}$ & Percentage \\
\hline Surgery & 49 & $85.96 \%$ \\
\hline Neoadjuvant chemotherapy & 6 & $10.52 \%$ \\
\hline Adjuvant chemotherapy & 43 & $75.43 \%$ \\
\hline Hormonal therapy & 48 & $84.21 \%$ \\
\hline Palliative chemotherapy & 3 & $5.26 \%$ \\
\hline Radiotherapy & 18 & $31.57 \%$ \\
\hline \multicolumn{2}{|c|}{ Table-4: Treatment modalities offered } \\
\hline
\end{tabular}

\begin{tabular}{|l|c|c|}
\hline Parameter & $\begin{array}{c}\text { Number of } \\
\text { patients }\end{array}$ & Percentage \\
\hline Lymph nodal involvement & 13 & $26.53 \%$ \\
\hline Positive surgical margins & 13 & $26.53 \%$ \\
\hline Grades & Grade I- 4 & $8.16 \%$ \\
& Grade II- 20 & $40.81 \%$ \\
& Grade III- 13 & $26.53 \%$ \\
\hline ER/ PR status & 2 out of 8 pa- & $25 \%$ \\
& tients positive & \\
\hline
\end{tabular}

Table-5: Histopathological attributes of tumor masses

\begin{tabular}{|c|c|c|c|}
\hline Tumor character & Very young ( $<30$ year) & Young $(>30-<40)$ & P value \\
\hline Total number & 12 & 45 & $<0.0001$ \\
\hline Mean duration of lump & 2.2 months & 4.2 months & - \\
\hline Mean tumor size & $5.6 \times 6.2 \mathrm{~cm}$ & $5.2 \times 5.4 \mathrm{~cm}$ & - \\
\hline Node positive patients (N1 + N2) & $\begin{array}{c}6 \text { patients } \\
(50 \%)\end{array}$ & $\begin{array}{l}20 \text { patients } \\
(35.08 \%)\end{array}$ & - \\
\hline Advanced clinical stage (III B + stage IV) & $\begin{array}{c}6 \text { patients } \\
(50 \%)\end{array}$ & $\begin{array}{l}13 \text { patients } \\
(28.88 \%)\end{array}$ & $P$ value $=0.3015$ \\
\hline Higher grade lesions (Gr II+ Gr III) & $\begin{array}{l}7 \text { patients } \\
(58.33 \%)\end{array}$ & $\begin{array}{l}26 \text { patients } \\
(57.77 \%)\end{array}$ & $P$ value $=0.9724$ \\
\hline ER/ PR status & Done in 3 , all negative & $\begin{array}{l}\text { Positive in } 2 \text { out of } 5 \\
\text { patients }\end{array}$ & $P$ value $=0.9333$ \\
\hline Number of patients with positive margins & $\begin{array}{c}4 \\
(33.33 \%)\end{array}$ & $\begin{array}{c}10 \\
(22.22 \%)\end{array}$ & $P$ value $=0.6551$ \\
\hline
\end{tabular}




\begin{tabular}{|c|c|c|c|}
\hline Tumor character & $\begin{array}{c}\text { Operable breast } \\
\text { cancers } \\
\text { (stage IIA+IIB+ IIIA) } \\
n=36\end{array}$ & $\begin{array}{c}\text { Advanced breast } \\
\text { cancers } \\
\text { (stage IIIB+IV) } \\
\mathrm{N}=19\end{array}$ & P value \\
\hline Average age & 35.19 & 34.94 & 0.8645 \\
\hline Mean duration of lump & 3.1 month & 2.94 month & 0.6868 \\
\hline Number of very young ( $\leq 30 \mathrm{yrs}$ ) patients & 6 & 6 & 0.3514 \\
\hline Number of nulliparous patients & 1 & 2 & 0.5432 \\
\hline Number of patients not breast fed & 3 & 1 & 0.7432 \\
\hline Number of patients with early age at $1^{\text {st }}$ pregnancy ( $<20$ yrs $)$ & 20 & 11 & 0.8679 \\
\hline Average diameter of lump & $4.82 \mathrm{~cm}$ & $8.10 \mathrm{~cm}$ & 0.00022 \\
\hline Node positivity (N1 + N2) & $16(44.44 \%)$ & $9(47.36 \%)$ & 0.8359 \\
\hline Higher grade tumors & 21 (58.33\%) & $11(57.89 \%)$ & 0.9750 \\
\hline
\end{tabular}

patients whose first pregnancy was before 20 years of age had advanced lesions with 5 patients having stage III A lesions and stage III B and stage IV showing 10 and 1 patients respectively. 22 out of 32 patients conceiving at $<20$ years had advanced histopathological grades ( $\mathrm{Gr}$ II $+\mathrm{Gr}$ III) which compounded to $68 \%$ of the group population. Amongst 3 women who conceived at age $>30$ years, one patient had stage 2B disease, another had stage III B disease, stage could not be labelled in one case because of Tx status.

Family history was inquired in every subject and was positive in two cases from $\leq 30$ years age group with both giving history of breast lump in second degree relatives. All the patients were inquired about the duration of lump. Duration of lump ranged from 1 month to 6 months duration with an average of 3.08 months. Increase in Duration of lump was associated with adverse presentation, 10 patients presented after $5 />5$ months and 7 out of $10(70 \%)$ presented with advanced T stage. 5 patients were having T4 lesions and 2 patients had T3 lesions.

Patients in very young age group ( $\leq 30$ years) had mean lump size of $5.6 \times 6.2 \mathrm{~cm}$ which was slightly larger than young age group (30- 40 years) which had mean lump size of $5.2 \times 5.4 \mathrm{~cm}$. No patient had small $<2 \mathrm{~cm}$ breast lump. Maximum patients fell under $>5 \mathrm{~cm}$ category highlighting the advanced presentation of young breast cancer. Mean lump size was $5.08 \times 5.32 \mathrm{cms}$. Two of the patients presented after prior lumpectomies hence lump size could not be made out. 22 patients i.e. $38.59 \%$ had left sided lesions. Majority of patients had right sided lumps with 35 patients (61.4\%). There were no patients with bilateral lumps. Most of the tumor masses originated in upper outer quadrant with a toll of 32 patients amounting to $56.14 \%$ of total bulk. Next to follow were central region tumors which were found in 13 patients or $22.80 \%$ of patients.

The analysis of clinical signs showed that the most common clinical sign in the studied cases was nipple retraction (19.29\%) followed by peau'de orange appearance (17.54\%) and nipple deviation (15.78\%). Satellite nodules and ulcers were seen in $8.77 \%$ patients each. There was no case with T0 or T1 lesion. Majority of the patients had either T3 (33.33\%), T2 (33.33\%) or T4 (31.57\%) lesions which was seen in 37 patients i.e. $64.8 \%$ of patients (figure-2).

When very young $(\leq 30$ years) patients were compared with young age group (30- 40 years) very young population had
$66.66 \%$ (8 out of 12) patients showing advanced tumor masses (T3, T4), same was found in 29 out of 45 patients of young age group (64.44\%).

Thus, almost half of the patients presented with nonpalpable axillary lymph nodes. Node positivity was more or less similar in $<30$ yrs age group and $>30$ years age group of patients. Three of the patients had metastatic symptoms of pleural effusion, liver metastasis and bony metastasis (low back pain). One of the patients with metastasis had nonpalpable lymph node while other two had N1 and N2 lymph nodes. Majority of the patients were having locally advanced III B stage. When very young patients ( $\leq 30$ years) from the study were compared with young patients (30- 40 years), very young had advanced malignancies in $50 \%$ i.e. 6 out of 12 patients in young age group were having stage III B or Stage IV disease (table-3). While in 30- 40 age group this was found in $28.88 \%$ patients with 12 patients having stage III B and single patient showing stage IV disease. Since two of the patients presented after lumpectomy were labelled as Tx hence staging could not be done. There were no patients who presented with stage I disease.

Diagnosed patient were treated with multimodality approach consisting of neoadjuvant chemotherapy, surgery, adjuvant chemotherapy, radiotherapy and hormonal therapy. Surgery was offered to 49 patients, surgeries which were offered were modified radical mastectomy in 42 patients i.e. $85.71 \%$ of the total surgeries, next in the shelf was simple mastectomy which was offered to 7 out of 49 patients or $14.28 \%$ of the total surgeries. Completion radiotherapy was given to 18 patients with positive margins or nodal involvement (table-4).

Minor complications like cuticular necrosis were top on the list of post-surgical complications of young breast cancer which was seen in 15 patients (26.31\%). Next to follow was seroma formation which was observed in 9 patients (15.78\%), severe complications like flap necrosis were rare however 3 patients had flap necrosis. $3.51 \%$ patients were found to have surgical site infection.

Infiltrating ductal carcinoma was the most common histopathological subtype of all which was found in 43 cases (75.43\%), least common was lobular variant which was seen in single patient aged 40 years, there were no cases of lobular carcinoma in under 30-year patients (figure-3).

Lymph nodal positivity was found in 13 patients i.e. $22.8 \%$ of patients. Surgical margins were found to be involved in 13 
patients. 33 out of 49 patients exhibited higher grade tumors which was around $77.3 \%$ of the total surgical specimens. Highlighting greater prevalence of higher grade tumors in early onset breast cancers. Very young group had 7 out of 12 patients showing advanced grades (grade II + grade III) i.e. $58.33 \%$ same was found in 26 pts of younger group i.e. $57.77 \%$, when margins were compared very young age group showed margin positivity in $33.33 \%$ patients as compared to $22.22 \%$ of younger age group (table-5).

While analyzing clinicopathological data we grouped patients in two categories operable breast cancer (stage II A + stage II B + stage III A) and advanced breast cancer (stage III B + stage IV), clinicodemographic data was analyzed between these two groups. $\mathrm{P}$ value for total number of patients in group was significant which means incidence of young breast carcinomas was higher than very young. Rest of the comparison was statistically insignificant (table-6).

When etiological factors in early onset breast cancers viz. Nulliparity, breast feeding and protective effect of early age at $1^{\text {st }}$ pregnancy when were independently tested in operable and advanced staged cancer groups no statistically significant association was found. The only factor which was statistically significant was average diameter of the lump (table-7).

2 patients expired during the study period. In both the patients there was metastatic spread of the carcinoma. First patient was pregnant and was found to have multiple lung metastasis in her first trimester of pregnancy and was advised termination of pregnancy. Patient died on the $4^{\text {th }}$ day of admission. Second patient had history of lumpectomy done and presented with ulceroproliferative growth, patient had multiple liver metastasis at the time of presentation, she was started on hormonal and palliation chemotherapy and succumbed after 6 weeks of treatment.

\section{DISCUSSION}

This was an observational study which was designed to find out the unique features of breast carcinomas in young female. Breast carcinoma as it was defined was the disease of post-menopausal women and same when presented in premenopausal young females was said to be associated with adverse clinicopathological features an attempt was made to find the same.

Carcinoma breast although a disease of postmenopausal women premenopausal or young breast carcinomas contributed $1-2 \%$ of the total breast cancer load. The incidence of carcinoma breast in the patients younger than 40 years was found to be $21 \%$ of overall cases of carcinoma breast. Similar incidence was reported by Sunita saxena et $\mathrm{al}^{9}$ who found the incidence of carcinoma breast in patients younger than 40 years to be $22 \%$. Low parity and nulliparity are important risk factors for development of carcinoma breast at relatively younger age. In our study we had 3 nulliparous females out of which two presented with advanced tumor masses (T4). Nulliparity has long been thought a risk factor for developing breast cancer Velentgas and Daling ${ }^{10}$ stated that breast cancer risk increases with late age at $1^{\text {st }}$ confinement and females with low parity.

In our study majority of the patients 32 (59.25\%) had first child birth before 20 years of age and only three patients
(5.55\%) had first child birth after 30 years. Thus, delayed first pregnancy as a reason for developing breast cancer was not common in our study with majority having given birth at earlier age suggesting role of other factors in causation. Some of the authors like Razif SM et $\mathrm{al}^{11}$ and B MacMohan et $\mathrm{al}^{12}$ found that the risk of developing breast cancer increases with increased age at first pregnancy.

We noted positive family history in two of very young $\leq 30$ patients $(3.5 \%)$ both had one second degree relative with breast lumps Anderson and Badzioch et $\mathrm{al}^{13}$ found that the patients with a positive family history was more likely to develop breast carcinoma at a younger age while the other authors like Ashutosh et al found that incidence of family history (13\%, 2 patients) was similar in both young breast cancer group and general population ${ }^{14}$.

In our cases most common presenting complaint was breast lump which was present in all the patients (100\%). Breast lump was the commonest presentation of breast cancers in studies done by H J G Bloom ${ }^{15}$, R Dirk Noyes et $\mathrm{al}^{16}$, and Paul $\mathrm{P}$ Rosen et $\mathrm{al}^{17}$. In our study when very young and young women with breast cancers were compared with respect to clinical stage histopathological grades ER/ PR status and post-operative margin status there was no statistically significant between the two groups. Thus, very young breast carcinomas do not differ from young breast carcinomas and the management depends upon the staging and grading of tumor ${ }^{18}$. We compared operable patients (stage II A+ II B + III A) with advanced tumors (stage III B+ IV) and found risk factors like nulliparity and reluctance of breast feeding was not associated with advanced presentation of disease. Early age at $1^{\text {st }}$ pregnancy as was thought to impart protective effect against breast cancer was documented however it does not govern the outlook of disease and has no statistically significant association with clinical stage. Tumors from advanced disease had larger lumps but there was no significant association of clinical stage with higher nodal positivity and higher-grade tumors. Similar conclusions were reported by Legorreta et $\mathrm{al}^{19}$ and Jeruss JS et al. ${ }^{20}$

\section{CONCLUSION}

our study has shown a major proportion of young females (those less than 40 years) with breast cancer presented with advanced stage signifying the importance of need of awareness of the fact that carcinoma breast should be suspected in any patient presenting with lump in breast unless proved otherwise. Proper awareness and screening programs can help in avoiding the delay in the diagnosis with its potential hazards.

\section{REFERENCES}

1. Eisemann N, Waldmann A, Katalinic A. Epidemiology of Breast Cancer - Current Figures and Trends. Geburtshilfe und Frauenheilkunde. 2013;73(2):130135.

2. Porter PL. Global trends in breast cancer incidence and mortality. Salud Publica Mex. 2009;51 Suppl 2: s141-6.

3. Tabár L, Duffy SW, Vitak B, Chen HH, Prevost TC. The natural history of breast carcinoma: what have we learned from screening? Cancer. 1999;86(3):449-62. 
4. Copson E, Maishman T, Gerty S, et al. Ethnicity and outcome of young breast cancer patients in the United Kingdom: the POSH study. British Journal of Cancer. 2014;110(1):230-241.

5. Cauchi JP, Camilleri L, Scerri C. Environmental and lifestyle risk factors of breast cancer in Malta-a retrospective case-control study. The EPMA Journal. 2016;7(1):20 .

6. WeiJ-T,Huang W-H,Du C-W,et al.Clinicopathological features and prognostic factors of young breast cancers in Eastern Guangdong of China. Scientific Reports. 2014;4:5360.

7. De Macêdo Andrade AC, Ferreira Júnior CA, Dantas Guimarães B, Pessoa Barros AW, Sarmento de Almeida G, Weller M. Molecular breast cancer subtypes and therapies in a public hospital of Northeastern Brazil. BMC Women's Health. 2014;14:110.

8. Eberlein TJ. Current management of carcinoma of the breast. Annals of Surgery. 1994;220:121-136.

9. Sunita Saxena et al clinic morphological patterns of breast cancer including family history in a New Delhi hosp, India. A cross sectional study. World journal of surgical oncology 2005;3:3:67.

10. Velentgas $P, D a l i n g R$ Risk factors for breast cancer in younger women Mongr natnl cancer institute 1994;16: 15- 22.

11. Razif S M, Sulaiman $\mathrm{S}$ et al contribution of reproductive factors and family history towards prmenopausal breast cancer risk in kualalampur Malaysia med j Malaysia 2011;66 (3):220- 226.

12. MacMahon B, Cole P, Lin TM, et al. Age at first birth and breast cancer risk. Bulletin of the World Health Organization. 1970;43(2):209-221.

13. Anderson and Badzioch MD risk of familial breast cancer. Cancer 1985; 56:383- 387.

14. Ashutosh Kothari et al breast carcinomas in women aged 25 or less cancer 2002;94; 606- 614.

15. H J G Bloom further studies on prognosis of cancer britisj journal of cancer 1950;4(2):347- 367 .

16. R Dirk Noyes Breast cancer in women 30 years and under Cancer 1982; 49: 1302-1307.

17. Paul peter Rosen Breast carcinomas in women 35 years of age or younger annals of surgery 1984;199(3):133142.

18. Lee H-B, Han W. Unique Features of Young Age Breast Cancer and Its Management. Journal of Breast Cancer. 2014;17(4):301-307.

19. Legorreta AP, Chernicoff HO, Trinh JB, Parker RG. Diagnosis, clinical staging, and treatment of breast cancer: a retrospective multiyear study of a large controlled population. Am J Clin Oncol. 2004;27(2):185-90.

20. Jeruss JS, Mittendorf EA, Tucker SL, et al. Staging of Breast Cancer in the Neoadjuvant Setting. Cancer research. 2008;68(16):6477-6481.

Source of Support: Nil; Conflict of Interest: None

Submitted: 01-07-2018; Accepted: 02-08-2018; Published online: 13-08-2018 